\title{
Involvement of the Central Nucleus and Basolateral Complex of the Amygdala in Fear Conditioning Measured with Fear-Potentiated Startle in Rats Trained Concurrently with Auditory and Visual Conditioned Stimuli
}

\author{
Serge Campeau and Michael Davis
}

Departments of Psychology and Psychiatry, Yale University School of Medicine and the Abraham Ribicoff Research Facilities of the Connecticut Mental Health Center, New Haven, Connecticut

\begin{abstract}
The goal of this work was to test the involvement of the central nucleus and basolateral complex of the amygdala In fear conditloning, using auditory and visual conditioned stimuli (CSs). The acoustic startle reflex in rats was used as the behavioral index of conditioning because startle is reliably enhanced in the presence of a conditioned stimulus (CS) previously paired with a footshock. Initially, differential conditioning procedures indicated reliable discrimination between a noise CS and a visual CS. Subsequently, the effects of amygdala lesions were evaluated when both modalities were paired with shocks in the same rats. Electrolytic or ibotenic acid lesions of the central nucleus of the amygdala blocked fear-potentiated startle to both auditory and visual CSs, consistent with the idea that the central nucleus serves as a response independent, final common relay for fear conditioning. Similarly, pre- or posttraining electrolytic or NMDA-induced lesions of the basolateral complex of the amygdala, which damaged the lateral nucleus, and most of the basolateral nucleus, disrupted fear-potentiated startle to both CS modalities. This finding is consistent with the suggestion that, in fear conditioning, the basolateral complex of the amygdala serves as an obligatory relay of sensory information from subcortical and cortical sensory areas to the central nucleus of the amygdala.
\end{abstract}

[Key words: amygdala, acoustic startle, lesion, fear conditioning]

Classical fear conditioning, obtained when a conditioned stimulus (CS) is paired with a noxious unconditioned stimulus (US), is a widely used procedure to investigate the neural basis of learning and memory. A relatively large number of studies employing a variety of animal species and behavioral indices have

\footnotetext{
Received Aug. 30, 1994; revised Sept. 23, 1994; accepted Sept. 30, 1994.

This research was supported by NIMH Grants MH-25642 and MH-47840, Research Scientist Development Award MH-00004 to Michael Davis, a grant from the Air Force Office of Scientific Research, and the State of Connecticut. We thank Drs. Thomas Carew, Edward Kairiss, David McCormick, and Allan Wagner for insightful discussion of this research. Thanks are extended to Younglim Lee for her comments on an earlier draft of the manuscript. This work was submitted by S.C. to the Graduate School of Yale University in partial fulfillment of the requirements for a Ph.D. degrec.

Correspondence should be addressed to Serge Campeau, Mental Health Research Institute, 205 Zina Pitcher Place, University of Michigan, Ann Arbor, MI 48109-0720.

Copyright (C) 1995 Society for Neuroscience $0270-6474 / 95 / 152301-11 \$ 05.00 / 0$
}

indicated the involvement of the amygdaloid complex in conditioned fear (for reviews, see Cohen, 1984; Sarter and Markowitsch, 1985; Davis, 1992; Kapp et al., 1992; LeDoux, 1992; McCabe et al., 1992; McGaugh et al., 1992). In many of these studies, direct amygdalofugal projections from the central nucleus of the amygdala have been determined to exert modulatory influences upon hypothalamic and brainstem nuclei mediating a variety of autonomic and somatomotor reactions characteristic of anxious or fearful behaviors. These findings strongly suggest that the central nucleus of the amygdala functions as a response independent, final relay which, upon activation by unconditioned or conditioned fear stimuli, coordinates the expression of a constellation of autonomic and somatomotor behaviors which are typically associated with general states of fear, stress, or anxiety (Davis, 1992; Kapp et al., 1992; LeDoux, 1992).

In turn, it has been suggested (LeDoux et al., 1990a) that the central nucleus of the amygdala might be activated via direct relays from neurons of the basolateral complex of the amygdala, which has conventionally included the lateral, basolateral, and basal nuclei (Krettek and Price, 1978; Ottersen, 1982; Price et al., 1987; McDonald, 1992). The basolateral complex of the amygdala appears to provide an essential link, necessary for conditioned fear, between cortical and subcortical sensory areas and the central nucleus. For instance, discrete electrolytic lesions of the lateral nucleus disrupt somatomotor and cardiac pressor conditioned responses to an auditory CS (LeDoux et al., 1990a). Similarly, combined neurotoxic lesions of the lateral and basolateral nuclei of the amygdala block the conditioned enhancement of the acoustic startle reflex by a visual CS (Sananes and Davis, 1992). To test directly the involvement of some of the nuclei of the basolateral complex of the amygdala in conditioned fear to auditory and visual CSs, combined lesions of the lateral and basolateral nuclei were carried out with both electrolytic and neurotoxic techniques in the present study. A within-subjects procedure was designed in which rats were concurrently conditioned to auditory and visual CSs. Conditioning was measured using the amplitude of the acoustic startle reflex, which is reliably enhanced in the presence of a CS previously paired with a footshock US (Brown et al., 1951).

The first experiment reports that pairing one stimulus modality with footshock produced reliable fear-potentiated startle that did not generalize to the other stimulus modality. This is a minimal prerequisite to begin assessing modality-specific versus modality-general lesion deficits. When both stimuli were paired with 
footshock, however, each CS displayed reliable and similar levels of fear-potentiated startle. The second experiment shows that electrolytic or excitotoxic lesions of the central nucleus of the amygdala block fear-potentiated startle in rats concurrently conditioned to auditory and visual CSs. This study also included preliminary anatomical retrograde transport data indicating that neurons of the central nucleus of the amygdala projecting directly to the nucleus reticularis pontis caudalis, an essential nucleus of the acoustic startle pathway modulated by fear (Hitchcock and Davis, 1991; Rosen et al., 1991; Koch and Ebert, 1993), are destroyed by ibotenic acid injections. The last set of experiments tested the involvement of the basolateral complex of the amygdala in the mediation of fear-potentiated startle to auditory and visual CSs, using electrolytic and excitotoxic lesions. The effects of pre- versus posttraining lesions were assessed to test the necessity of the basolateral complex in the acquisition and expression of fear-potentiated startle.

\section{Materials and Methods}

\section{Subjects}

Experimentally naive male albino Sprague-Dawley rats weighing 320$400 \mathrm{gm}$ (Charles River Co., Kingston, NY) were used. The rats were housed in wire cages $(17 \times 35 \times 45 \mathrm{~cm})$ in groups of two or three with water and laboratory chow continuously available, and maintained on a $12 \mathrm{hr}: 12 \mathrm{hr}$ light-dark cycle (lights on at 7:00 A.M.). Rats were acclimated to the colony rooms for 2-3 weeks before experimental manipulation.

\section{Apparatus}

The equipment used was similar to that described previously (see Cassella and Davis,' 1986, and Campeau and Davis, 1992, for details). Briefly, five separate stabilimeters were used, each consisting of a $8 \times 15$ $\times 15 \mathrm{~cm}$ Plexiglas and wire mesh cage suspended within a $25 \times 20 \times$ $20 \mathrm{~cm}$ heavy steel frame. The floor of each stabilimeter was composed of four stainless steel bars $(6.0 \mathrm{~mm}$ in diameter $)$, spaced $20 \mathrm{~mm}$ apart (center to center), through which electric shocks could be delivered. Within the steel frame, the cage was compressed between four springs above and a $5 \times 5 \mathrm{~cm}$ rubber cylinder below, with an accelerometer (Endevco 2217E) located between the cage and the rubber cylinder. Cage movement resulted in displacement of the accelerometer, the output of which was amplified (Endevco model 104), digitized and stored on a Macintosh II computer. Startle amplitude was defined as the maximum accelerometer voltage that occurred during the first $200 \mathrm{msec}$ after startle stimulus onset. The stabilimeters were housed on two shelves within a ventilated, sound-attenuating chamber $(2.5 \times 2.5 \times 2$ m; Industrial Acoustic Co.).

The startle stimuli were $50 \mathrm{msec}$ (rise-decay, $5 \mathrm{msec}$ ) bursts of white noise of variable intensity. Background white noise $(0-20 \mathrm{kHz})$ of 55 dB (SPL) was provided throughout all experiments. The auditory CS was produced by a white noise generator and band-pass filtered, with the low- and high-pass filters both set at $2 \mathrm{kHz}(24 \mathrm{~dB} /$ octave attenuation), at an intensity of $70 \mathrm{~dB}$ (SPL). Relatively low-frequency auditory CSs were previously found to produce reliablc fear-potentiated startle (Campeau and Davis, 1992). The auditory CS was delivered by a speaker located approximately $70 \mathrm{~cm}$ in front of each cage. An $8 \mathrm{~W}$ fluorescent light bulb (rise-decay, $100 \mu \mathrm{sec} ; 800 \mathrm{ft}$ lamberts intensity), located approximately $5 \mathrm{~cm}$ behind, and at a level $5 \mathrm{~cm}$ above the grid floor of each startle cage, served as the visual CS. The cages' grid floor could be electrified by constant current shock-generator scramblers at an intensity of $0.5 \mathrm{~mA}$ (see Cassella and Davis, 1986, for current derivation).

\section{Behavioral procedures}

Matching. On the first $2 \mathrm{~d}$ of all experiments, rats were placed in the stabilimeter cages and 5 min later presented with 30 startle stimuli at a $30 \mathrm{sec}$ interstimulus interval. Intensities of 90,95 , and $105 \mathrm{~dB}$ (SPL) were used with 10 startle stimuli at each intensity. Startle stimuli were presented in a balanced, irregular sequence with the restriction that each of the three intensities had to occur in every three trial blocks. The mean startle amplitude across the 30 startle stimuli on the last matching day was used to assign rats into several groups with similar means before training, or surgery.

Training. On the day after the last matching test, rats $(n=27)$ were placed in the stabilimeter cages and 5 min later presented with the first of ten $3.7 \mathrm{sec}$ auditory CSs, mixed with 10 additional presentations of the $3.7 \mathrm{sec}$ visual CS. For one group of rats $(n=9)$ in the initial experiment, each presentation of the auditory CS coterminated with a $0.5 \mathrm{sec}, 0.5 \mathrm{~mA}$ footshock. For another group of rats $(n=9)$, each presentation of the visual CS coterminated with a similar footshock. For the third group of rats $(n=9)$, both auditory and visual CSs coterminated with footshock. The CSs were irregularly presented at a variable intertrial interval of $3.0 \mathrm{~min}$ (range, $1.5-4.5 \mathrm{~min}$ ), with the restriction that no more than three consecutive CSs of the same modality were presented. Training was conducted on each of 2 consecutive days, for a total of 20 presentations of each CS type.

Testing. Rats were placed back in the stabilimeters and 5 min later presented with 30 startle eliciting stimuli alone $(95 \mathrm{~dB})$. Thirty seconds following the last initial startle stimulus, 40 additional $95 \mathrm{~dB}$ startle stimuli were presented, consisting of 30 startle stimuli alone, 5 startle stimuli occurring $3.2 \mathrm{sec}$ after the onset of the $3.7 \mathrm{sec}$ auditory CS, and 5 startle stimuli occurring $3.2 \mathrm{sec}$ after the onset of the $3.7 \mathrm{sec}$ visual CS. The startle stimuli were presented at a fixed interstimulus interval of $30 \mathrm{sec}$, and the occurrence of each trial type was semirandom with the restriction that each block of eight trials contained six startle stimulus alone trials, one auditory CS trial, and one visual CS trial.

Posttraining lesion studies. For all subsequent lesion experiments, all rats received auditory and visual CSs coterminating with footshock Rats $(n=104)$ were first trained on each of 2 consecutive days, and given a potentiated startle test on the next day, as described above. On the basis of this test, 88 rats showing greatcr than $50 \%$ startle potentiation to each CS modality were divided into unoperated, sham-operated or lesioned groups with similar levels of fear-potentiated startle to each CS modality. Surgery was performed $24-48 \mathrm{hr}$ after the potentiated startle test. After a $10 \mathrm{~d}$ recovery period, rats were tested with the same initial fear-potentiated startle test.

Pretraining lesion studies. Rats $(n=19)$ were divided into unoperated, sham-operated, or lesioned groups with similar startle responses on the basis of the matching test. Surgery was performed $24-48 \mathrm{hr}$ after matching. After a $7 \mathrm{~d}$ recovery period, rats were trained on each of 2 consecutive days and tested for fear-potentiated startle $24 \mathrm{hr}$ later. Thus, in both pre- and posttraining studies, the lesion-to-test interval was kept constant at $10 \mathrm{~d}$, but testing occurred either 1 or $10 \mathrm{~d}$ after training. This particular design was chosen because rats show similar fear-potentiated startle levels when tested from 1 to $30 \mathrm{~d}$ after training (Campeau et al., 1990).

Footshock sensitivity. Following pretraining lesion studies, rats were tested for their reactivity to footshock. They were placed in the stabilimeters and $5 \mathrm{~min}$ later presented with a train of 10 footshocks, of 0.5 $\mathrm{sec}$ duration, at a rate of $1 \mathrm{shock} / \mathrm{sec}$. Each rat received a total of 10 footshock trains, two at each of $0.2,0.4,0.6,0.8$, and $1.0 \mathrm{~mA}$ intensity, in an ascending/descending order. This procedure was performed to determine if lesions altered footshock sensitivity, at least as judged by this measure.

\section{Surgical procedures}

General. Rats were anesthetized by intraperitoneal injections of 400 $\mathrm{mg} / \mathrm{kg}$ of chloral hydrate (Sigma) dissolved in sterile saline $(0.9 \% \mathrm{NaCl})$ when electrolytic lesions were to be made. For ibotenic acid or NMDAinduced excitotoxic lesions, rats were anesthetized by intraperitoneal injection of $50 \mathrm{mg} / \mathrm{kg}$ of Nembutal (Abbott). Rats were placed in a Kopf stereotaxic instrument equipped with blunt earbars, an incision of the skin overlying the skull was made, and small burr holes were drilled through the skull to allow penctration of clectrodes or injectors. Bilateral lesions were performed in all experiments, except for preliminary unilateral ibotenic acid lesions of the central nucleus, in combination with retrograde tracer injection in the nucleus reticularis pontis caudalis. Following the surgical procedures, the scalp incision was closed with surgical stainless steel clips, and rats were kept warm and under observation until recovery from anesthesia. They were subsequently housed two per cage to minimize isolation stress.

Electrolytic lesions. Electrolytic lesions were made with stainless steel electrodes $(0.25 \mathrm{~mm}$ in diameter $)$ insulated except for $0.5 \mathrm{~mm}$ of the tip. A constant current source generated dc anodal current for all electrolytic lesions at an intensity of $0.1 \mathrm{~mA}$. Sham electrolytic lesions consisted of lowering the electrode $1.0 \mathrm{~mm}$ above the ventral lesion 
coordinate without passing current. All coordinates are in reference to the flat skull system of Paxinos and Watson (1986). If disruption of fear-potentiated startle was obtained with electrolytic lesions, the effects of excitotoxic lesions were evaluated in additional rats.

Excitotoxic lesions. Neuronal cell loss was induced by ibotenic acid or $N$-methyl-D-aspartic acid (Sigma), dissolved in sodium phosphate buffer ( $\mathrm{pH} 7.4$ ), at the indicated volumes and concentrations. The injector (Hamilton 1 or $2 \mu \mathrm{l}$ syringes) was lowered into the brain and left in place $5 \mathrm{~min}$ before and $10 \mathrm{~min}$ after each injection. The rate of infusion was $0.05 \mu \mathrm{l} / \mathrm{min}$. Sham surgeries involved the same manipulations except that only the vehicle solution (sodium phosphate buffer) was injected.

Anatomical tracing. The fluorescent retrograde tracer Fluoro-Gold (Fluorochrome Inc., Englewood, CO) was dissolved in distilled, deionized water at a concentration of $4 \%$. Deposits were achieved by pressure injections via a $1 \mu 1$ Hamilton syringe fitted with a glass capillary tube (1B120F) pulled and broken to a tip diameter of $40-50 \mu \mathrm{m}$.

Lesions of the central nucleus of the amygdala. Rats were given pustlraining electrolytic lesions of the central nucleus of the amygdala $(n=7)$ by passing current for a duration of $70 \mathrm{sec}$ at $1.6 \mathrm{~mm}$ posterior, $4.0 \mathrm{~mm}$ lateral, and $8.6 \mathrm{~mm}$ ventral to bregma, and $2.6 \mathrm{~mm}$ posterior, $4.6 \mathrm{~mm}$ lateral, and $8.1 \mathrm{~mm}$ ventral. Sham-operated $(n=5)$ and unoperated $(n=6)$ rats served as controls.

In a preliminary study, excitotoxic lesions of the central nucleus were assessed by injecting five rats unilaterally with $0.2 \mu \mathrm{l}$ of a $10 \mu \mathrm{g} / \mu \mathrm{l}$ solution of ibotenic acid at $2.2 \mathrm{~mm}$ posterior, $4.3 \mathrm{~mm}$ lateral, and 8.3 $\mathrm{mm}$ ventral. During the same operation, these rats also received bilateral injections of $100 \mathrm{nl}$ of $4 \%$ Fluoro-Gold into the nucleus reticularis pontis caudalis, at a level where neurons of the central nucleus of the amygdala terminate (Rosen et al., 1991). This procedure tested the effectiveness of ibotenic acid to destroy neurons of the central nucleus, especially those from its medial aspect, shown to directly innervate the nucleus reticularis pontis caudalis (Rosen et al., 1991; Koch and Ebert, 1993).

For the fear-potentiated startle study, 13 rats received posttraining, bilateral ibotenic acid injections using the parameters described above. Sham-operated $(n=12)$ and unoperated $(n=11)$ rats served as controls.

Lesions of the basolateral complex of the amygdala. Posttraining electrolytic lesions of the lateral and basolateral nuclei of the amygdala ( $n$ $=11$ ) were achieved by passing current for $45 \mathrm{sec}$ at $2.3 \mathrm{~mm}$ posterior, $5.0 \mathrm{~mm}$ lateral, and $7.8 \mathrm{~mm}$ ventral, and for $55 \mathrm{sec}$ at $3.6 \mathrm{~mm}$ posterior, $5.2 \mathrm{~mm}$ lateral, and $8.0 \mathrm{~mm}$ ventral. Posttraining excitotoxic lesions of the basolateral complex $(n=15)$ were obtained by injecting $0.12 \mu \mathrm{l}$ of a solution of $20 \mu \mathrm{g} / \mu \mathrm{I}$ of NMDA at $3.0 \mathrm{~mm}$ posterior, $5.1 \mathrm{~mm}$ lateral, and $7.9 \mathrm{~mm}$ ventral. Sham-operated rats $(n=8)$ served as controls. Additional rats were given similar, pretraining, NMDA-induced lesions of the basolateral complex $(n=11)$, including 8 additional sham-operated controls.

\section{Histology}

At the end of the experiments, lesioned rats were anesthetized with an overdose of chloral hydrate and perfused with physiological saline followed by $10 \%$ buffered formalin phosphate. Brains were removed and stored in a solution of $30 \%$ sucrose in formalin for at least $2 \mathrm{~d}$. Brains were sectioned in a cryostat, where every fifth $40 \mu \mathrm{m}$ section in the lesioned area was placed on gelatin coated slides. After drying, the slides were stained with cresyl violet in the case of electrolytic lesions, or by the Kluver-Barrera method in the case of most excitotoxic lesions, to assess separately damage to cell bodies versus fibers of passage. For fluorescence microscopy, the slides, once dry, were cleared for $10 \mathrm{~min}$ in xylenes, and then coverslipped with DPX (Fluka, Switzerland).

\section{Data reduction and statistical analysis}

The lesions were reconstructed on plates photocopied from the rat brain atlas of Paxinos and Watson (1986). Inclusion of rats in statistical analyses was strictly based on the adequacy of the lesions, without knowledge of the behavioral data of individual rats. Criteria for adequate lesions included bilateral damage of the area investigated throughout most of its extent, with incomplete and inconsistent damage of surrounding areas. In the case of the central nucleus, the lesions had to include the medial aspect of the central nucleus, which is the area directly projecting to the nucleus reticularis pontis caudalis (Hitchcock and Davis, 1991; Rosen et al., 1991). For the basolateral complex, the lesions had to include the lateral nucleus of the amygdala, with additional but variable damage to the basolateral nucleus. This criteria was selected on the basis of the previous finding of LeDoux et al. (1990a), that lesions restricted to the lateral nucleus of the amygdala were sufficient to disrupt conditioned fear to an auditory stimulus.

The initial 30 startle stimuli alone were used to habituate the rats to the acoustic startle stimuli and were not used for statistical analysis. Mean startle amplitudes were computed for the startle stimulus alone trials and the auditory and visual CS trials, respectively, for each rat. In addition, the mean startle amplitude on the startle stimulus alone trials was subtracted from the mean startle amplitude on the respective auditory and visual CS trials, providing a difference score for each CS modality, for each rat. Repeated-measures ANOVAs were first conducted on the mean startle amplitude data, to detect significant levels of fear-potentiated startle (trial type effect), and possible interactions with treatment (CS-US pairing in the first experiment or surgical conditions in subsequent experiments). Because the detection of significant interactions mainly reflects group differences between their respective startle stimulus alone trial means and auditory or visual CS trial means, these interactions were further analyzed by carrying out additional oneway ANOVAs on difference scores for each CS modality. A main effect of a one-way ANOVA on difference scores is numerically identical to the interaction term obtained from mean startle amplitude data computed for each CS modality, but multiple mean comparisons are easier to visualize graphically and to compute using the difference score data. However, difference score analyzes were performed only in cases where no reliable effects had been obtained after an initial one-way ANOVA was performed on startle stimulus alone trials (i.e., no group differences could be attributed merely to changes in startle responsiveness). These analyses were complemented, when required, by post hoc multiple mean comparisons (Tukey HSD or Newman-Keuls) or $t$ tests.

For the shock-induced activity test, mean activity was computed by averaging activity across the 10 consecutive shock presentations for each intensity. The results of the ascending and descending shock series were further averaged for each shock intensity. Standard repeated-measures or one-way ANOVAs, complemented, when required, by $t$ tests, were then conducted.

\section{Results}

\section{Concurrent conditioning to auditory and visual CSs}

As shown in Figure 1, rats displayed reliable fear-potentiated startle to the auditory or visual CS only when these stimuli had becn explicitly paired with footshock. A repcated-measures ANOVA on trial type (startle stimulus alone, auditory CS, and visual CS) and training condition (auditory, visual, and auditory-visual) revealed a reliable training condition $\times$ trial type interaction, $F(4,48)=11.26, p<0.001$. No effects, however, were obtained from a one-way ANOVA on the startle stimulus alone means $(p>0.05)$. A separate analysis on the auditory CS difference scores indicated a reliable training condition effect, $F(2,24)=8.02, p<0.002$, which reflected the fact that potentiated startle only occurred in the auditory and auditory-visual groups, but not in the visual group ( $p$ values $<0.05$, Tukey post hoc multiple mean comparisons). Similar analyses of the visual CS difference scores indicated a reliable training condition effect, $F(2,24)=11.74, p<0.001$, with significant differences between the visual and auditory-visual groups versus the auditory group ( $p$ values $<0.05$ ). For the auditory-visual group, significant potentiation was obtained to both the auditory and visual CSs $(p<0.05)$, the magnitude of which was significantly correlated (Pearson correlation coefficient, $0.68, p<0.05$ ).

\section{Lesions of the central nucleus of the amygdala}

From the seven rats that received bilateral electrolytic lesions aimed at the central nucleus of the amygdala, two were excluded from the study because they sustained mostly unilateral damage to the central nucleus. In the other rats $(n=5)$, the medial aspect of the central nucleus of the amygdala was completely lesioned, with inconsistent damage to the lateral and basolateral nuclei of 

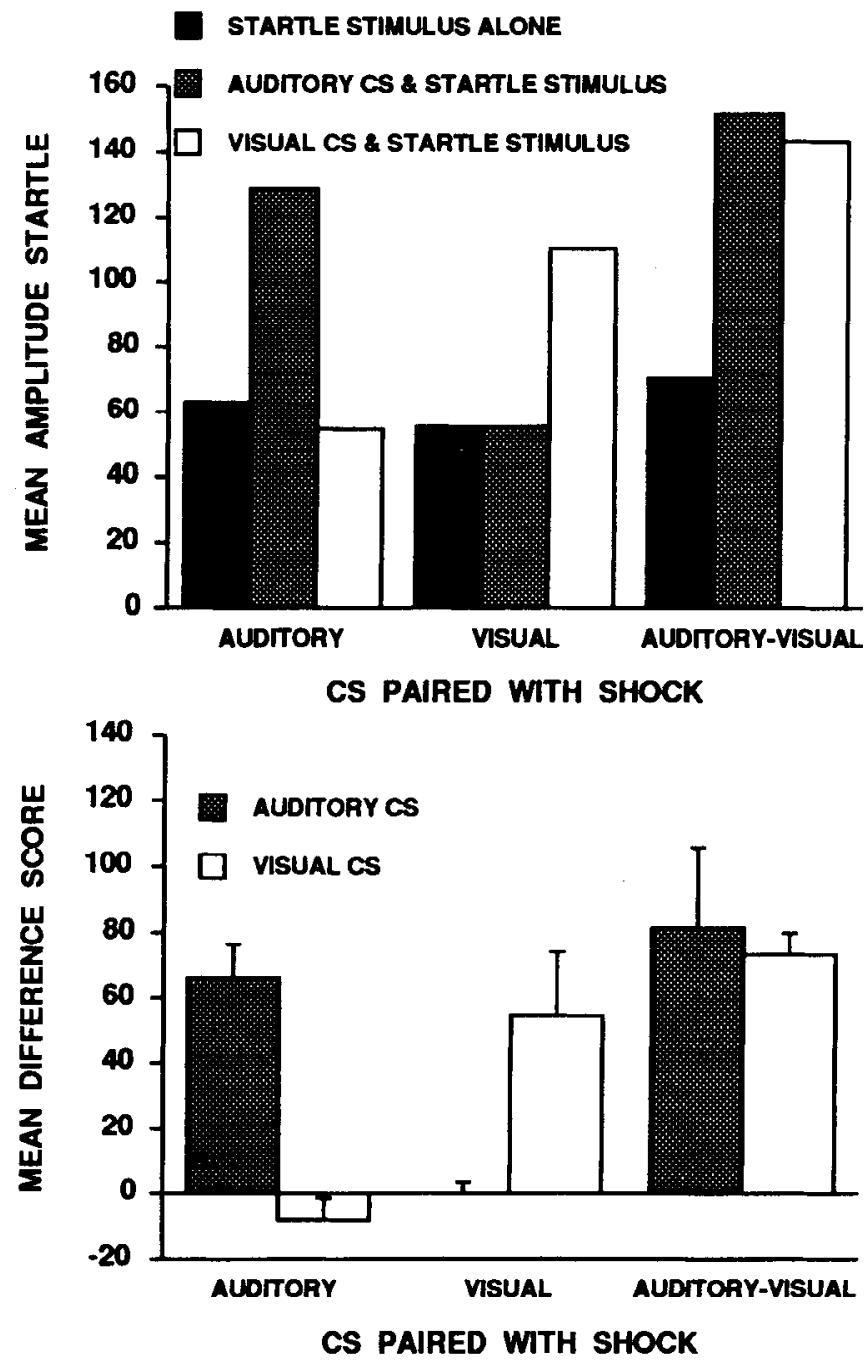

Figure 1. The upper panel presents mean startle amplitude on startle stimulus alone trials, auditory CS and startle stimulus, and visual CS and startle stimulus trials. The training conditions included rats for which only the auditory CS was paired with shock, only the visual CS was paired with shock, or both auditory and visual CSs were paired with shock. The lower punel shows the subtracted mean difference scores (+SEM) for the auditory and visual CS trials for each of the training conditions.

the amygdala, the amygdalo-striatal transition area, the ventral caudate-putamen and the ventral globus pallidus. Histological reconstructions of the smallest and largest electrolytically induced central amygdala lesions are shown in Figure 2. The upper panel of Figure 3 shows that complete abolition of fear-potentiated startle to both the auditory and visual CSs was produced by posttraining electrolytic lesions of the central nucleus of the amygdala [trial type $\times$ treatment condition interaction $F(4,26)$ $=4.88, p<0.005]$. Additional ANOVAs indicated no treatment effect on startle stimulus alone trials, $F(2,13)=0.02, p>0.05$, but reliable treatment effects on auditory and visual CS difference scores, $F(2,13)=15.52$, and $4.98, p$ values $<0.025$, respectively. Mean difference scores of the central amygdala lesioned group differed reliably from those of the sham-operated rats on both CS modalities ( $p<0.05$, Tukey). The central nucleus lesioned rats did not show significant potentiation to the auditory or visual $\operatorname{CS}[t(4)=0.99$ and 2.05 , all $p$ values $>0.05$, respectively], but both the unoperated and sham-operated groups did $[t(5)=6.15$ and 3.03 , and $t(4)=4.99$ and 2.95 , all $p$ values $<0.05$, respectively]. No differences were found between groups on the prelesion startle test [trial type $\times$ treatment condition interaction, $F(4,26)=0.74, p>0.05$ ], indicating that all groups had similar levels of potentiation prior to surgery (data not shown).

To initially evaluate the effectiveness of ibotenic acid to destroy those cells in the central nucleus that project directly to the startle pathway, retrograde labeling of these neurons, obtained after injection of the tracer Fluoro-Gold in the nucleus reticularis pontis caudalis, was performed after unilateral intraamygdala injection of ibotenic acid in five rats. Two rats sustained ibotenic acid injections in the central nucleus with bilateral placement of the retrograde tracer in the nucleus reticularis pontis caudalis. In two additional rats, the ibotenic acid injections missed the central nucleus, and the fifth rat only showed unilateral Fluoro-Gold placement in the nucleus reticularis pontis caudalis. Figure 4 demonstrates that Fluoro-Gold labeling was completely abolished on the side of the ibotenic acid injection, in a rat with accurate ibotenic acid and Fluoro-Gold injections. This result could not be attributed to a misplacement of Fluoro-Gold into the nucleus reticularis pontis caudalis, because neurons of the substantia innominata, which also project to this nucleus (Rosen et al., 1991), were clearly observed on the lesioned side (not shown). Similar results were observed in the other rat with accurate ibotenic acid and Fluoro-Gold injections. Due to the high mortality rate of rats receiving tracer injections in the brainstem, however, this procedure was not performed in conditioned rats given bilateral central amygdala ibotenic acid injections.

From the 13 rats that received bilateral ibotenic acid injections aimed at the central nucleus, seven sustained very incomplete damage to the central nucleus, mostly because the injections did not appear to diffuse into the medial portion of the central nucleus. The six rats retained for analysis sustained greater than $90 \%$ bilateral destruction of the medial aspect of the central nucleus of the amygdala, with inconsistent damage to the lateral and basolateral nuclei of the amygdala, the amygdalo-striatal transition area, and the ventral caudate-putamen. Histological reconstructions of the smallest and largest ibotenic acid-induced excitotoxic lesions of the central nucleus of the amygdala, and a photomicrograph of a brain section showing intermediate damage, are shown in Figure 2. The lower panel of Figure 3 shows that the six rats sustaining bilateral ibotenic acid lesions of the central nucleus also had a complete disruption of potentiated startle to both the auditory and visual CSs [treatment condition $\times$ trial type interaction, $F(4,52)=4.63, p<0.003]$. A reliable treatment condition effect was obtained from the ANOVA on auditory difference scores, $F(2,26)=6.23, p<0.006$, because lesioned rats displayed significantly lower potentiation than the unoperated or sham-operated rats ( $p$ values $<0.05$, Tukey). A similar effect of treatment was seen with the visual CS difference scores, $F(2,26)=11.56, p<0.001$, where central amygdala lesioned rats differed reliably from the unoperated and sham-operated rats ( $p$ values $<0.005$ ). Unoperated and shamoperated rats displayed significant startle potentiation to both the auditory and visual CSs (all $p$ values $<0.005$ ), whereas the central amygdala lesioned rats did not, $t(5)=0.08$ and $0.04, p$ values $>0.05$. These results cannot be attributed to differences on startle stimulus alone responsiveness, $F(2,26)=1.19, p>$ 0.05 , or different fear-potentiated startle levels between the treat- 

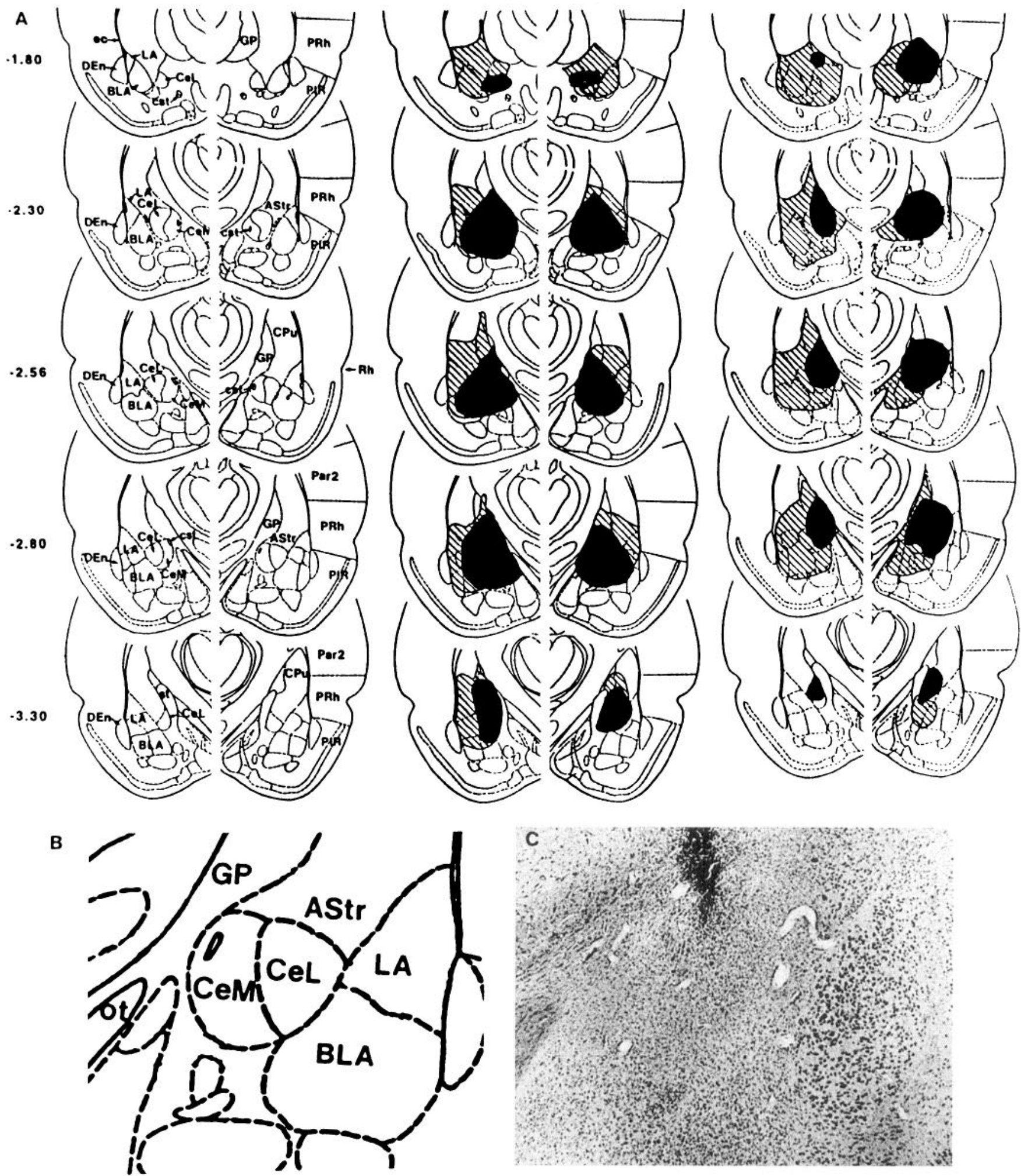

Figure 2. A, Histological reconstructions of the smallest (black) and largest (hatched) electrolytic (center) and ibotenic acid (right) lesions aimed at the central nucleus of the amygdala. Serial coronal plates through the extent of the central nucleus of the amygdala are shown on the left (the negative numbers to the left indicate posterior distance from bregma; adapted from Paxinos and Watson, 1986). The lateral aspects of each side of the brain with medial aspects removed are shown to conserve space. See Appendix for abbreviations. $B$, Drawing at the approximate level of the coronal section in $C$ outlining individual areas. $C$, Coronal section through the amygdala of a rat sustaining moderate ibotenic acid lesions of the central nucleus. Note the sparing of basolateral complex neurons to the right. 

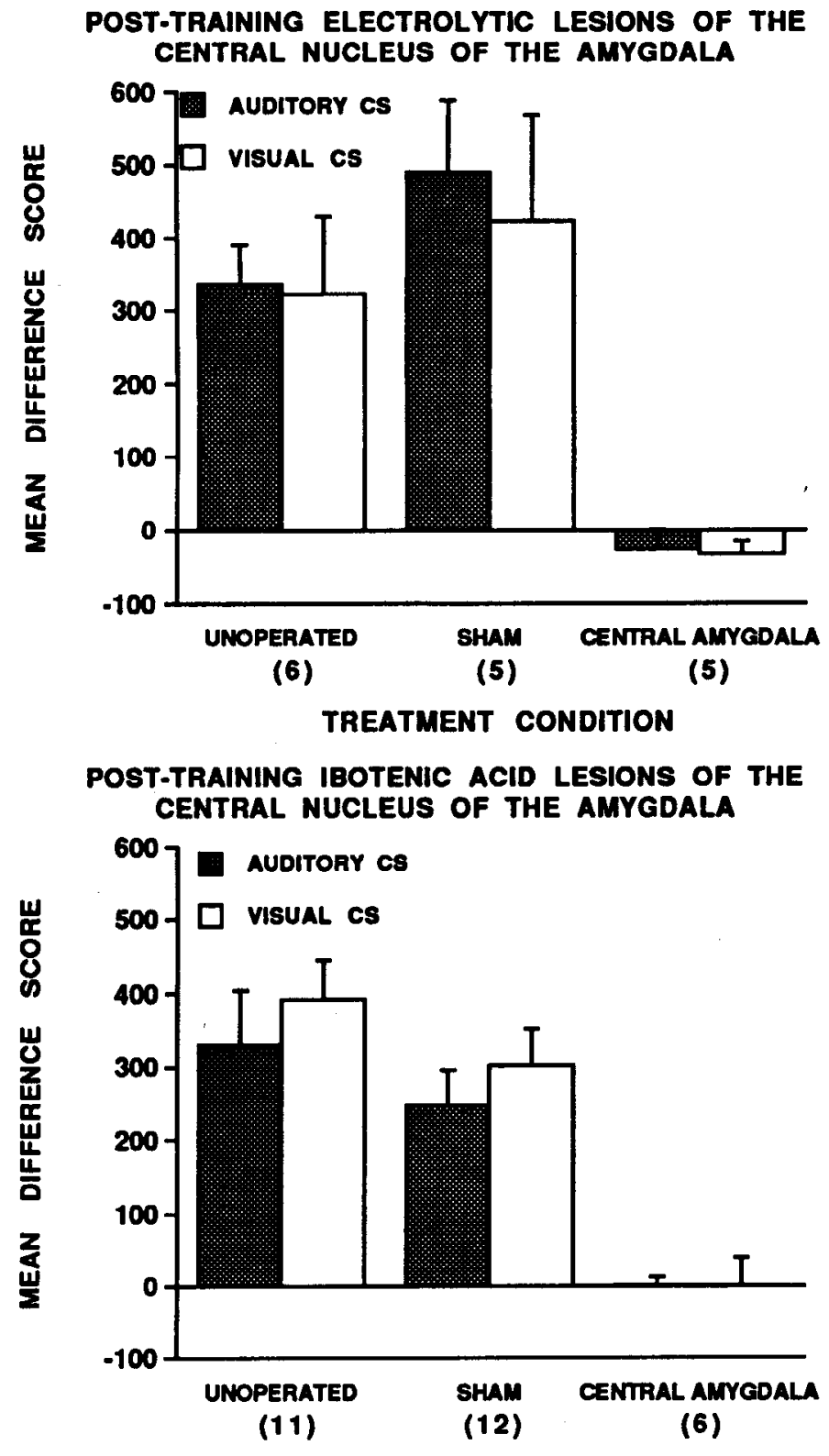

TREATMENT CONDITION

Figure 3. Mean difference scores (+SEM) on auditory and visual CS trials for rats sustaining electrolytic (upper panel) or NMDA (lower panel) lesions of the central nucleus of the amygdala. Mean amplitude startle on the startle stimulus alone trials was 333.2 for unoperated rats, 340.1 for sham-operated rats, and 323.0 for rats sustaining posttraining electrolytic lesions of the central nucleus. Mean amplitude startle on the startle stimulus alone trials was 321.8 for unoperated rats, 259.5 for sham-operated rats, and 244.8 for rats sustaining bilateral ibotenic acid lesions of the central nucleus. Numbers in parentheses indicate the number of rats in each condition.

ment conditions before surgery [treatment condition $\times$ trial type interaction, $F(4,52)=0.94, p>0.05$; data not shown].

\section{Lesions of the basolateral complex of the amygdala}

Three of 11 rats with electrolytic and 3 of 15 rats sustaining NMD $\Lambda$ basolateral amygdala complex lesions had damage extending all the way to the medial aspect of the central nucleus of the amygdala, and were excluded from the study. In the remaining rats $(n=20)$, the bilateral lesions were relatively large and always included the rostral lateral nucleus, with sparing, in a few rats, of its most posterior aspects, whether the lesions were produced electrolytically or with NMDA. The basolateral nucleus of the amygdala was damaged in most rats, but almost invariably spared some neurons in its ventral aspect, at least unilaterally. Damage to the central nucleus of the amygdala was observed in some rats, but only to its lateral aspect, and unilaterally. Inconsistent damage to the amygdalo-striatal transition area, the dorsal endopiriform nucleus, the anterior perirhinal cortex, the caudate-putamen and the globus pallidus, was observed unilaterally in some rats. Figure 5 provides reconstructions of the smallest and largest electrolytic and NMDA lesions sustained by rats retained in this study. As seen from the lower panel of Figure 5, excitotoxic NMDA-induced lesions of the basolateral amygdala complex spared neurons in the central (especially its medial aspect) and basolateral amygdala subnuclei of a rat sustaining intermediate basolateral complex damage.

The upper panel of Figure 6 illustrates that posttraining electrolytic or excitotoxic basolateral complex lesions abolished fear-potentiated startle to the auditory and visual CSs [trial type $X$ treatment condition interaction, $F(4,50)=9.31, p<0.001$ ] A reliable treatment effect was obtained on auditory CS difference scores, $F(2,25)=16.41, p<0.001$, with reliable differences between each lesioned group and the sham-operated rats $(p$ values $<0.05$, Tukey). Only the sham-operated rats demonstrated significant startle potentiation to the auditory CS, $t(7)=$ $4.21, p<0.004$ (lesioned groups, $p$ values $>0.05$ ). Potentiation to the visual CS was also disrupted in lesioned rats, $F(2,25)=$ $13.18, p<0.001$, with each lesion group differing from the sham-operated rats ( $p$ values $<0.05$, Tukey). Potentiation to the visual CS was reliable in the sham-operated, $t(7)=4.12, p<$ 0.05 , and NMDA lesioned rats, $t(11)=2.61, p<0.05$, but not in electrolytically lesioned rats, $t(7)=0.18, p>0.05$. These results could not be attributed to different startle responsiveness among groups $[F(2,25)=0.51, p>0.05]$, or different potentiated startle levels to either CSs prior to surgery [trial type $\times$ treatment condition interaction, $F(4,50)=0.42, p>0.05$, data not shown].

Three of 11 rats that received pretraining NMDA lesions aimed at the basolateral amygdala complex had to be discarded because of incomplete bilateral lesions. The lesions sustained by the other rats $(n=8)$ were similar to those described above for rats sustaining posttraining lesions. The lower panel of Figure 6 indicates that NMDA-induced lesions of the basolateral complex of the amygdala before training produced a marked deficit in fear-potentiated startle to the auditory and visual CSs [trial type $\times$ treatment condition interaction, $F(2,28)=3.50, p<0.04]$. Subsequent individual $t$ tests revealed significant potentiation to the auditory CS in sham-operated rats, $t(7)=8.0, p<0.001$, but not in lesioned rats, $t(7)=2.03, p>0.05$. Similarly, significant fear-potentiated startle was observed to the visual CS in sham-operated rats, $t(7)=3.74, p<0.01$, but not in rats sustaining basolateral complex lesions, $t(7)=1.65, p>0.05$. These deficits could not be attributed to different startle stimulus responsiveness, $F(1,14)=0.41, p>0.05$. Likewise, no treatment condition effect, $F(1,14)=1.14, p>0.05$, or treatment condition $\times$ shock intensity interaction, $F(4,56)=0.64, p>0.05$, were obtained on the shock reactivity test, suggesting that lesioned rats had relatively normal reactions to footshocks (Table $1)$. 

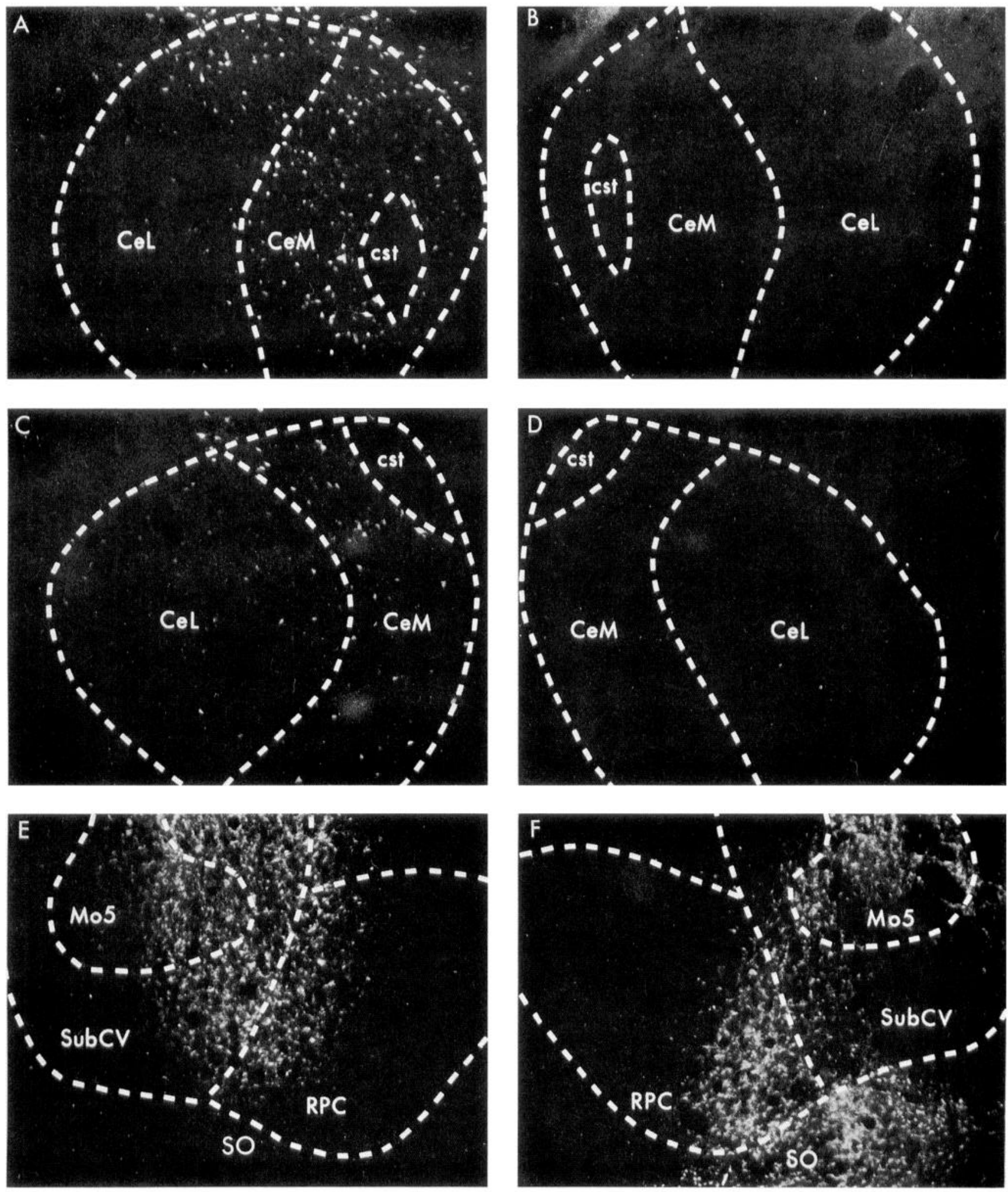

Figure 4. A, Photomicrograph of the fluorescent labeling obtained in an intact section of the anterior central nucleus of the amygdala after FluoroGold injection in the nucleus reticularis pontis caudalis. Note the density and number of labeled neurons, especially in the medial central nucleus $(\mathrm{CeM})$, around the commissure of the stria terminalis $(c s t) . B$, Photomicrograph of the contralateral central nucleus, which was injected with ibotenic acid, in the same rat, at the same level as in $A$. Note the absence of fluorescent labeling. $C$ and $D$ are similar to $A$ and $B$, respectively, but at a more posterior level. $E$ and $F$ show the injection sites on the respective sides of transport $(A, C$, and $B, D)$. Each injection reached the part of the nucleus reticularis pontis caudalis known to be critical for the acoustic startle reflex. See Appendix for abbreviations. 

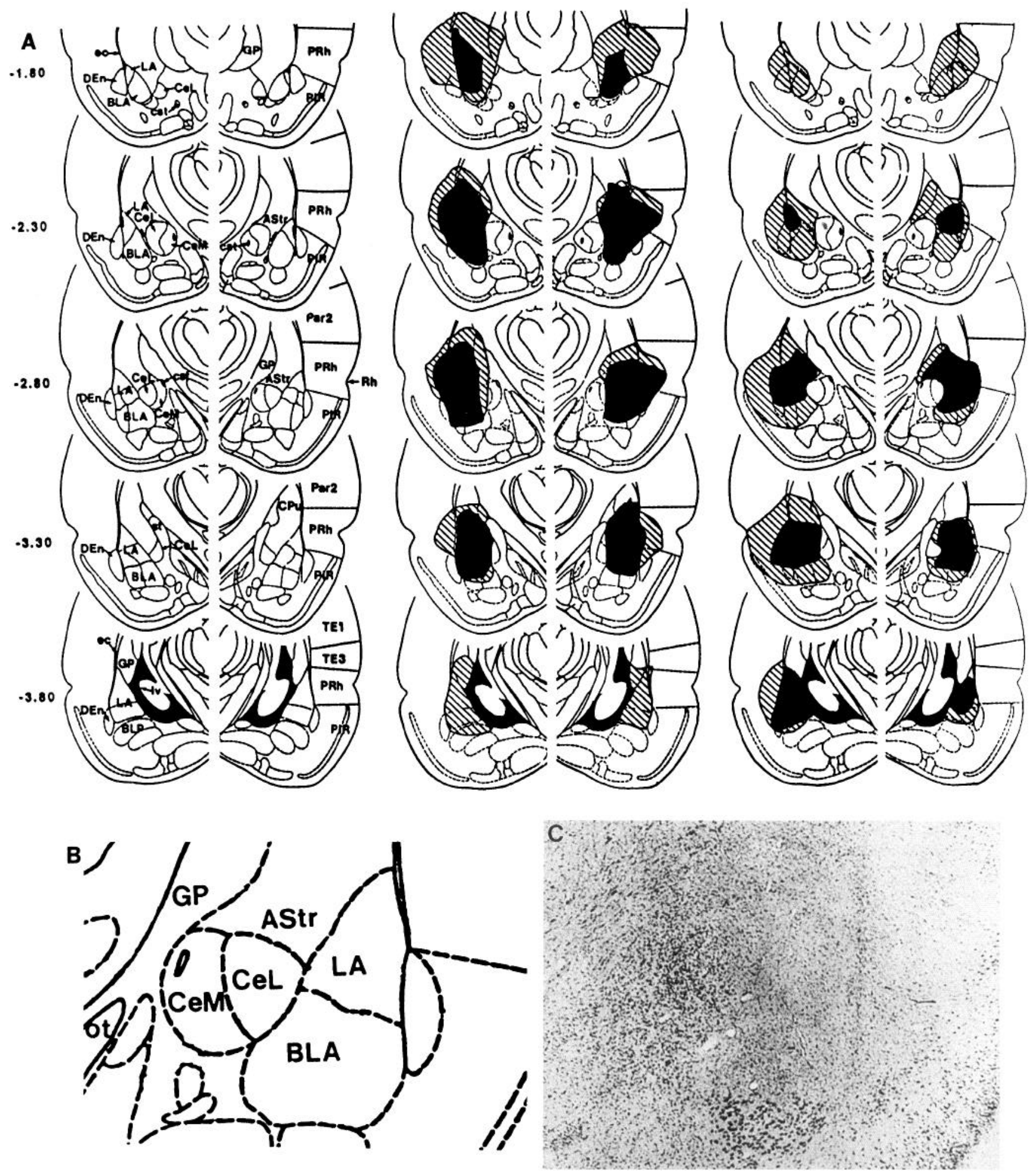

Figure 5. A, Histological reconstructions of the smallest (black) and largest (hatched) electrolytic (center) and NMDA (right) lesions aimed at the lateral nucleus of the amygdala. Serial coronal plates through the extent of the basolateral complex of the amygdala are shown on the left. The lateral aspects of each side of the brain with medial aspects removed are shown to conserve space. See Appendix for abbreviations. $B$, Drawing at the approximate level of the coronal section in $C$ outlining individual areas. $C$, Coronal section through the amygdala of a rat sustaining moderate NMDA lesions of the basolateral complex. Note the sparing of basolateral neurons in its ventral extent, and of central amygdala neurons to the left 
Table 1. Footshock-induced reactivity (SEM) in rats sustaining NMDA-induced lesions of the basolateral complex of the amygdala

\begin{tabular}{llllrl} 
& \multicolumn{2}{l}{ Shock intensity $(\mathrm{mA})$} \\
\cline { 2 - 6 } Treatment & 0.2 & 0.4 & 0.6 & \multicolumn{1}{l}{0.8} & \multicolumn{1}{l}{1.0} \\
\hline Sham & $132.1(24.0)$ & $530.4(35.8)$ & $831.5(54.7)$ & $1111.3(85.3)$ & $1395.3(69.1)$ \\
NMDA & $110.6(15.0)$ & $457.3(70.0)$ & $738.1(79.3)$ & $919.3(97.7)$ & $1320.2(151.8)$ \\
\hline
\end{tabular}

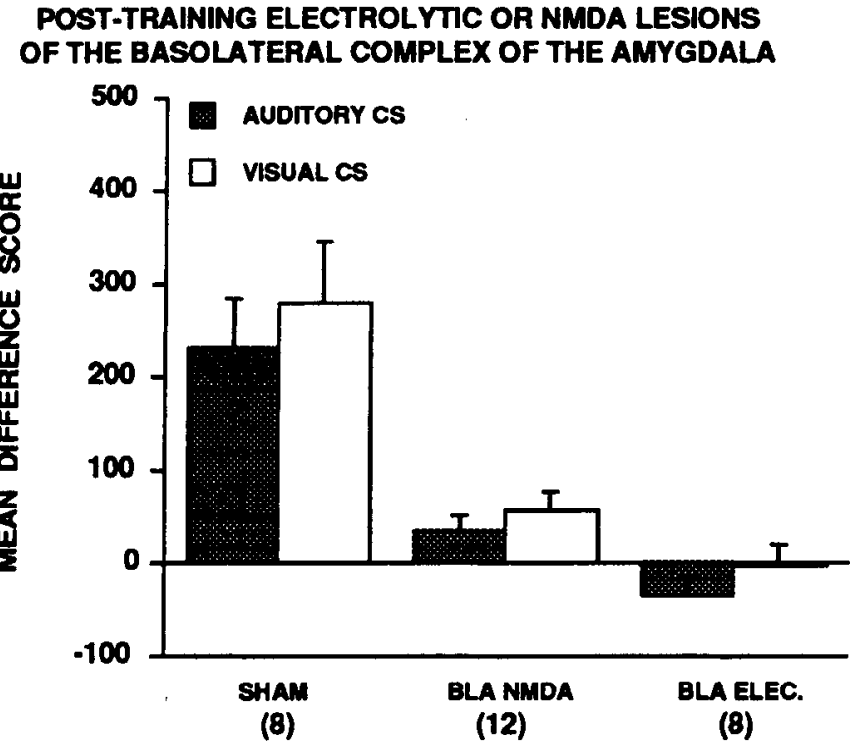

TREATMENT CONDITION

PRE-TRANING NMDA LESIONS OF THE BASOLATERAL COMPLEX OF THE AMYGDALA

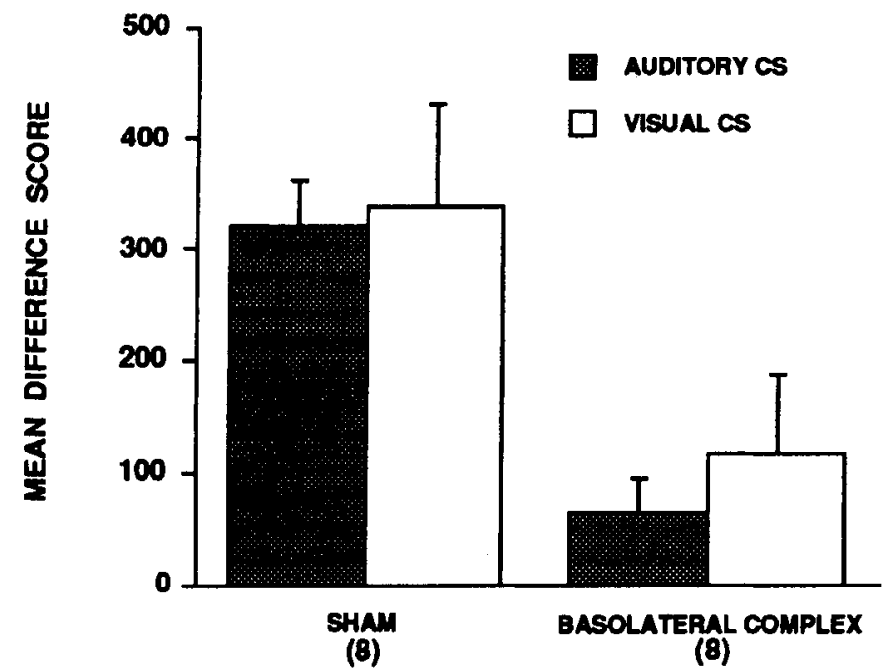

TREATMENT CONDITION

Figure 6. Mean difference scores (+SEM) on auditory and visual CS trials for rats sustaining post- (upper panel) or pretraining (lower panel) lesions of the basolateral complex of the amygdala. Mean amplitude startle on the startle stimulus alone trials was 263.2 for rats sustaining sham surgery, 259.7 for rats sustaining NMDA-induced lesions, and 318.6 for rats sustaining electrolytic lesions of the basolateral complex of the amygdala. Mean startle amplitude on the startle stimulus alone trials was 380.5 for sham-operated rats, and 359.9 for rats sustaining NMDA lesions of the basolateral complex of the amygdala before training.

\section{Discussion}

The initial behavioral study showed that pairing a CS of one modality with footshock led to fear-potentiated startle to that CS, without obscrvable gencralization to a CS of a different modality. This finding allowed the determination of the involvement of the central nucleus and basolateral complex of the amygdala in the conditioning of different modality CSs (auditory and visual) simultaneously, in a within-subjects design. The apparent absence of generalization of fear-potentiated startle from one CS to another reduced the possibility that putative lesion deficits might be missed due to cross-modal generalization, which might be especially problematic in the event that some nuclei would be involved in modality specific processing.

A reevaluation of the role of the central nucleus of the amygdala in fear-potentiated startle using the present within-subjects procedures confirmed prior findings (Hitchcock and Davis, 1986, 1987; Kim and Davis, 1993) that bilateral electrolytic lesions of the central nucleus of the amygdala block fear-potentiated startle to auditory and visual CSs. The preliminary study using bilateral injections of the retrograde tracer Fluoro-Gold in the nucleus reticularis pontis caudalis, combined with unilateral injection of fiber-sparing excitotoxic doses of ibotenic acid into the central nucleus of the amygdala, demonstrated that these lesions destroyed neurons, including those in the medial aspect of the central nucleus, which directly innervate the acoustic startle pathway (Hitchcock and Davis, 1991; Rosen et al., 1991; Koch and Ebert, 1993). Following this demonstration then, bilateral excitotoxic lesions of the central nucleus of the amygdala were also found to disrupt fear-potentiated startle to the auditory and visual CSs, consistent with previous findings (Hitchcock and Davis, unpublished observations). The present results extended the finding of Hitchcock and Davis (1987), obtained with a pure tone CS, to a narrow-band noise CS centered at a relatively low frequency $(2000 \mathrm{~Hz})$, used in the present studies. Overall, these data support the view that neurons of the central nucleus of the amygdala function as a CS and response independent, final common relay nucleus mediating the expression of many fear reactions upon its activation by aversive stimuli (see Davis, 1992; Kapp et al., 1992; and LeDoux, 1992, for reviews).

Activation of the central nucleus of the amygdala by conditioned aversive stimuli has recently been proposed to be mediated, at least in part, by the lateral and/or basolateral nuclei of the amygdala (LeDoux et al., 1990a). This is anatomically supported by the direct innervation of the central nucleus from nuclei of the basolateral complex of the amygdala (Krettek and Price, 1978; Ottersen, 1982; Price et al., 1987; McDonald, 1992; Stefanacci et al., 1992). The present studies demonstrated that electrolytic or excitotoxic posttraining lesions of the basolateral complex of the amygdala, which spared, in many rats, some ventral basolateral and most basal nuclei neurons, disrupted fear- 
potentiated startle to both auditory and visual CSs. Importantly, in most rats, these lesions spared central amygdala neurons, especially those located in the medial aspect of the central nucleus. Similar deficits were also observed with pretraining excitotoxic lesions of the basolateral complex of the amygdala. These results are consistent with the previous finding that the lateral nucleus of the amygdala is necessary for the conditioning of somatomotor and cardiac pressor responses to auditory CSs (LeDoux et al., 1990a), and extends these results to excitotoxically induced lesions, and generalizes them to the visual modality. Also, because many basolateral nucleus neurons were spared in most rats, especially after excitotoxic lesions, the results suggest that lesions restricted to the lateral nucleus of the amygdala may produce just as severe deficits as with complete lateral and basolateral nuclei excitotoxic lesions (Sananes and Davis, 1992).

Because fear-potentiated startle was disrupted by posttraining lesions, the basolateral complex of the amygdala appears necessary in the expression and/or retrieval of previously acquired fear conditioned responses. More recently, this conclusion has been supported by the fact that infusion into the basolateral complex of the AMPA receptor antagonist CNQX, immediately prior to testing (Izquierdo et al., 1993; Kim et al., 1993), blocked the expression of conditioned fear. The role of the basolateral complex in the acquisition of conditioned fear cannot be assessed unambiguously given the present lesion results, because the posttraining deficits mask possible pretraining effects. However, prior studies have indicatcd that infusion of NMDA receptor antagonists directly into the basolateral complex of the amygdala immediately before the acquisition phase of fear conditioning disrupts later retention (Miserendino et al., 1990; Campeau et al., 1992; Kim and McGaugh, 1992; Fanselow and Kim, 1994). In contrast, similar infusions immediately prior to testing or infusions into the central nucleus prior to training (Fanselow and Kim, 1994), do not inpair the retention of conditioned fear responses. Overall, the lesion and drug injection findings support the necessity of the basolateral complex of the amygdala in fear conditioning, and further suggest its involvement in the acquisition and retention of conditioned fear responses. Additional studies will be required to assess the specific contributions of the lateral and basolateral nuclei in these different processes.

A parsimonious explanation for the disruptive effects of basolateral complex lesions can be based on the assumed disconnection of the central nucleus from the sensory inputs provided mainly by the lateral nucleus of the amygdala. However, the above data do not exclude the possibility that polysynaptic pathways, intra- or extra-amygdaloid, might be involved in the transmission of information from the lateral nucleus to the central nucleus. For instance, although present, only weak projections have been observed from the lateral to the central nucleus of the amygdala, and these appcar to contact the lateral aspect of the central nucleus exclusively (Krettek and Price, 1978; Price et al., 1987). A more likely transmission pathway to the central nucleus appears to include at least one additional synapse in the basolateral nucleus, which is innervated by the lateral nucleus, and in turn innervates the medial aspect of the central nucleus (Krettek and Price, 1978; Wakefield, 1979; Ottersen, 1982; Price et al., 1987; Stefanacci et al., 1992). Mure extensive multisynaptic extra-amygdaloid pathways could involve projections from the lateral to the basolateral nucleus, which in turn has been reported to project to various cortical areas, including insular, medial frontal, prelimbic, and infralimbic cortices (Krettek and Price, 1977; McDonald and Jackson, 1987; Price et al.,
1987). Each of these cortical areas has been reported to innervate the central nucleus of the amygdala (Veening, 1978; Ottersen, 1982; McDonald and Jackson, 1987; Price et al., 1987; Hurley et al., 1991). Nlthough posttraining lesions of many of these cortical areas fail to block fear-potentiated startle (Rosen et al., 1991), additional studies still will be required to determine the exact pathway by which the lateral and basolateral nuclei exert their influences upon the central nucleus of the amygdala.

Overall, this series of experiments indicates that the central nucleus of the amygdala might be the target of inputs from the basolateral complex, either directly or through multisynaptic intra- or extra-amygdaloid connections. These nuclei are part of a neural circuit necessary in the mediation of fear conditioning to auditory and visual conditioned stimuli, and probably to other sensory modalities as well (Blanchard and Blanchard, 1972; Sananes and Campbell, 1989; Phillips and LeDoux, 1992). In the following companion article (Campeau and Davis, 1995), an evaluation of some of the inputs to the lateral nucleus of the amygdala was carried out to test their involvement in fear-potentiated startle to auditory and visual CSs.

\section{Appendix}

$\begin{array}{ll}\text { List of } & \text { Abbreviations } \\ \text { AMPA } & \text { a-amino-3-hydroxy-5-methyl-4-isoxazolepropionate } \\ \text { AStr } & \text { amygdalostriatal transition area } \\ \text { BLA } & \text { basolateral nucleus of the amygdala } \\ \text { CeM } & \text { medial aspect of the central nucleus of the amygdala } \\ \text { CeL } & \text { lateral aspect of the central nucleus of the amygdala } \\ \text { CNQX } & \text { 6-cyano-7-nitro-quinoxaline-2,3-dione } \\ \text { CPu } & \text { caudate-putamen } \\ \text { cst } & \text { commissure of the stria terminalis } \\ \text { DEn } & \text { dorsal endopiriform nucleus } \\ \text { ec } & \text { external capsule } \\ \text { GP } & \text { globus pallidus } \\ \text { lv } & \text { lateral ventricle } \\ \text { LA } & \text { lateral nucleus of the amygdala } \\ \text { Mo5 } & \text { fifth motor nucleus } \\ \text { ot } & \text { optic tract } \\ \text { Par2 } & \text { sccondary somatoscnsory cortcx } \\ \text { PIR } & \text { piriform cortex } \\ \text { PRh } & \text { perirhinal cortex } \\ \text { Rh } & \text { rhinal sulcus } \\ \text { RPC } & \text { nucleus reticularis pontis caudalis } \\ \text { st } & \text { stria terminalis } \\ \text { SO } & \text { superior olivary nuclei } \\ \text { SPFPC } & \text { subparafascicular nucleus } \\ \text { SubCV } & \text { ventral subcoeruleus nucleus } \\ \text { TE1 } & \text { primary auditory cortex } \\ \text { TE3 } & \text { secondary auditory cortex } \\ & \end{array}$

\section{References}

Blanchard DC, Blanchard RJ (1972) Innate and conditioned reactions to threat in rats with amygdaloid lesions. J Comp Physiol Psychol 81:281-290.

Brown JS, Kalish HI, Farber IE (1951) Conditioned fear as revealed by magnitude of startle response to an auditory stimulus. J Exp Psychol 41:317-328.

Campeau S, Davis M (1992) Fear potentiation of the acoustic startle reflex using noises of various spectral frequencies as conditioned stimuli. Animal Learning Behav 20:177-186.

Campeau S, Davis M (1995) Involvement of subcortical and cortical afferents to the lateral nucleus of the amygdala in fear conditioning measured with fear-potentiated startle in rats trained concurrently with auditory and visual conditioned stimuli. J Neurosci 15:23122327.

Campeau S, Liang KC, Davis M (1990) Long-term retention of fearpotentiated startle following a short training session. Animal Learning Behav 18:462-468.

Campeau S, Miserendino MJD, Davis M (1992) Intra-amygdala infusion of the $N$-methyl-D-aspartate receptor antagonist AP5 blocks ac- 
quisition but not expression of fear-potentiated startle to an auditory conditioned stimulus. Behav Neurosci 106:569-574.

Cassella JV, Davis M (1986) The design and calibration of a startle measurement system. Physiol Behav 36:377-383.

Cohen DH (1984) Identification of vertebrate neurons modified during learning: analysis of sensory pathways. In: Primary neural substrates of learning and behavioral change (Alkon DL, Farley J, eds), pp 129154. Cambridge: Cambridge UP.

Davis M (1992) The role of the amygdala in conditioned fear. In: The amygdala: neurobiological aspects of emotion, memory, and mental dysfunction (Aggleton JP, ed), pp 255-305. New York: Wiley-Liss.

Fanselow MS, Kim JJ (1994) Acquisition of contextual Pavlovian fear conditioning is blocked by application of an NMDA receptor antagonist D,L-2-amino-5-phosphonovaleric acid to the basolateral amygdala. Behav Neurosci 108:210-212.

Hitchcock J, Davis M (1986) Lesions of the amygdala, but not the cerebellum or red nucleus, block conditioned fear as measured with the potentiated startle paradigm. Behav Neurosci 100:11-22.

Hitchcock JM, Davis M (1987) Fear-potentiated startle using an auditory conditioned stimulus: effect of lesions of the amygdala. Physiol Behav 39:403-408.

Hitchcock JM, Davis M (1991) Efferent pathway of the amygdala involved in conditioned fear as measured with the fear-potentiated startle paradigm. Behav Neurosci 105:826-842.

Hurley KM, Herbert H, Moga MM, Saper CB (1991) Efferent projections of the infralimbic cortex of the rat. J Comp Neurol 308:249 276.

Izquierdo I, Bianchin M, Bueno E, Silva M, Zanatta MS, Walz R, Ruschel AC, Da Silva RC, Paczko N, Medina JH (1993) CNQX infused into rat hippocampus or amygdala disrupts the expression of memory of two different tasks. Behav Neural Biol 59:1-4.

Kapp BS, Whalen PJ, Supple WF, Pascoe JP (1992) Amygdaloid contributions to conditioned arousal and sensory information processing. In: The amygdala: neurobiological aspects of emotion, memory, and mental dysfunction (Aggleton JP, cd), pp 229-254. Ncw York: WileyLiss.

Kim M, Davis M (1993) Electrolytic lesions of the amygdala block acquisition and expression of fear-potentiated startle even with extensive training, but do not prevent re-acquisition. Behav Neurosci 107:580-595.

Kim M, McGaugh JL (1992) Effects of intra-amygdala injections of NMDA receptor antagonists on acquisition and retention of inhibitory avoidance task. Brain Res 585:35-48.

Kim M, Campeau S, Falls WA, Davis M (1993) Infusion of the nonNMDA receptor antagonist CNQX into the amygdala blocks the expression of fear-potentiated startle. Behav Neural Biol 59:5-8.

Koch M, Ebert U (1993) Enhancement of the acoustic startle response by stimulation of an excitatory pathway from the central amygdala/basal nucleus of Meynert to the pontine reticular formation. Exp Brain Res 93:231-241.

Krettek JE, Price JL (1977) Projections from the amygdaloid complex to the cerebral cortex and thalamus in the rat and cat. J Comp Neurol 172:687-722.

Krettek JE, Price JL (1978) A description of the amygdaloid complex in the rat and cat with observations on intra-amygdaloid axonal connections. J Comp Neurol 178:255-280.

LeDoux JE (1992) Emotion and the amygdala. In: The amygdala: neu- robiological aspects of emotion, memory, and mental dysfunction (Aggleton JP, ed), pp 339-351. New York: Wiley-Liss.

LeDoux JE, Cicchetti P, Xagoraris A, Romanski LM (1990a) The lateral amygdaloid nucleus: sensory interface of the amygdala in fear conditioning. J Neurosci 10:1062-1069.

McCabe PM, Schneiderman N, Jarrell TW, Gentile CG, Teich AH, Winters RW, Liskowsky D (1992) Central pathways involved in classical differential conditioning of heart rate responses in rabbits. In: Learning and memory: the behavioral and biological substrates (Gormezano I, Wasserman EA, eds), pp 321-346. Hillsdale, NJ: Erlbaum.

McDonald AJ (1992) Cell types and intrinsic connections of the amygdala. In: The amygdala: neurobiological aspects of emotion, memory, and mental dysfunction (Aggleton IP, ed), op 67-96. New York: Wiley-Liss.

McDonald AJ, Jackson TR (1987) Amygdaloid connections with posterior insular and temporal cortical areas in the rat. J Comp Neurol 262:59-77.

McGaugh JL, Introini-Collison IB, Cahill L, Kim M, Liang KC (1992) Involvement of the amygdala in neuromodulatory influences on memory storage. In: The amygdala: neurobiological aspects of emotion, memory, and mental dysfunction (Aggleton JP, ed), pp 431451. New York: Wiley-Liss.

Miserendino MJD, Sananes CB, Melia KR, Davis M (1990) Blocking of acquisition but not expression of conditioned fear-potentiated startle by NMDA antagonists in the amygdala. Nature 345:716-718.

Ottersen OP (1982) Connections of the amygdala of the rat. IV. Corticoamygdaloid and intraamygdaloid connections as studied with axonal transport of horseradish peroxidase. J Comp Neurol 205:30-48.

Paxinos G, Watson C (1986) The rat brain in stereotaxic coordinates, 2d ed. Orlando: Academic.

Phillips RG, LeDoux JE (1992) Differential contribution of amygdala and hippocampus to cued and contextual fear conditioning. Behav Neurosci 106:274-285.

Price JL, Russchen FT, Amaral DG (1987) The limbic region. II. The amygdaloid complex. In: Handbook of chemical neuroanatomy, Vol 5, Integrated systems of the CNS, Pt I (Bjorklund A, Hokfelt T, Swanson LW, eds), pp 279-388. Amsterdam: Elsevier.

Rosen JB, Hitchcock JM, Sananes CB, Miserendino MJD, Davis M (1991) A direct projection from the central nucleus of the amygdala to the acoustic startle pathway: anterograde and retrograde tracing studies. Behav Neurosci 105:817-825.

Sananes CB, Campbell BA (1989) Role of the central nucleus of the amygdala in olfactory heart rate conditioning. Behav Neurosci 103: $519-525$.

Sananes CB, Davis M (1992) N-Methyl-D-aspartate lesions of the lateral and basolateral nuclei of the amygdala block fear-potentiated startle and shock sensitization of startle. Behav Neurosci 106:72-80.

Sarter M, Markowitsch HJ (1985) Involvement of the amygdala in learning and memory: a critical review, with emphasis on anatomical relations. Behav Neurosci 99:342-380.

Steffanacci L, Farb CR, Pitkanen A, Go G, LeDoux JE, Amaral D (1992) Projections from the lateral nucleus to the basal nucleus of the amygdala: a light and electron microscopic. PHA-L study in the rat. J Comp Neurol 323:586-601.

Veening JG (1978) Cortical afferents of the amygdaloid complex in the rat: an HRP study. Neurosci Lett 8:191-195.

Wakefield C (1979) The intrinsic connections of the basolateral amygdaloid nuclei as visualized with the HRP method. Neurosci Lett 12: $17-21$. 